\title{
Philosophy, Chemistry and Education: An Introduction
}

\author{
Sibel Erduran
}

Published online: 4 August 2012

(C) Springer Science+Business Media B.V. 2012

In 1997, Eric Scerri published a short paper with the thought-provoking title, Are chemistry and philosophy miscible? (Scerri 1997). The use of a chemistry metaphor in communicating the marriage of the seemingly disparate fields — chemistry and philosophy—was insightful, particularly given the observation that chemists and philosophers seem to lack interest in each others' work:

\begin{abstract}
One of the characteristics of chemists is, that most have no interest in the philosophy of science...The disinterest appears to work in both directions. Modern philosophers very seldom give even a passing mention to modern chemical issues (Michael Polanyi and Rom Harré are among the few exceptions I know of). Recently, a few philosophers have attempted to discuss 'scientific practice'; but generally they have not included chemical practice. It is as if philosophers have believed that the way physics is 'done' was the way that all science is, or should be, done. (Physicists, no doubt, are the source of this opinion.) (Good 1999, pp. 65-66)
\end{abstract}

Such criticisms that expose the lack interest in the philosophical aspects of chemistry follow earlier observations that history of chemistry has often escaped the attention of chemists and chemical educators:

Chemists, compared with other scientists, have relatively little interest in the history of their own subject. This situation is reflected, and perpetuated, by the antihistorical character of most chemical education (Stephen Brush quoted by Kauffman 1989, p. 81).

The pattern of disinterest in the meta-perspectives on chemistry seems to be changing since the mid-1990s when some philosophers and chemists alike started challenging the position of physics as the representative paradigm of science (Scerri 2000; van Brakel 2000). Since then, an increasing number of books, journals, conferences, and associations focused on the articulation of how chemistry could be understood from a philosophical perspective. Unfortunately the same dynamism of scholarship cannot be attributed to the uptake of philosophy of chemistry in chemical education research and practice. The development of new perspectives on how philosophical aspects of chemistry can inform education has had

S. Erduran $(\bowtie)$

Graduate School of Education, University of Bristol, 35 Berkeley Square, Bristol, UK

e-mail: sibel.erduran@bristol.ac.uk

S. Erduran

Kristianstad University, Kristianstad, Sweden 
rather slow progress. Science \& Education was one of first journals to dedicate space to the work of educators preoccupied with the synthesis of perspectives from philosophy of chemistry in chemical education (e.g. Erduran 2001). This special edition is testament to the journal's vision in pushing boundaries for innovative scholarship, and it illustrates the small but growing interest of philosophers, educators and chemists alike in capitalising on the philosophical aspects of chemistry for the improvement of chemical education.

The volume consists of papers that deal with a range of issues raised in philosophy of chemistry in application to chemical education. One set of papers focus on the nature of chemical knowledge, particularly in relation to models, explanations and laws. Andrea Woody uses the ideal gas law as an example in reviewing contemporary research in philosophy of science concerning scientific explanation. She clarifies the inferential, causal, unification, and erotetic conceptions of explanation. Chemical laws is the primary focus of Emma Tobin's work. She provides an overview of the laws in chemistry, and reflects on the recent debates on the particular and universal nature of laws, concluding that while generalisations in chemistry are diverse and heterogeneous, a distinction between idealizations and approximations can nevertheless be used to successfully taxonomise them. Agustin Aduriz-Bravo challenges the received, syntactic conception of scientific theories and argues for a model-based account of the nature of science. The significance of models and modeling in chemistry is further highlighted by Jose A. Chamizo who presents a typology of models and their relation to modeling. Merce Izquierdo-Aymerich argues for the generation of chemical criteria from the history and philosophy of chemistry for informing the design of chemistry curriculum.

A second set of papers focus on particular epistemological themes that have generated a great deal of debate in philosophy of chemistry in recent years. The authors extend these debates to the curricular, textbook and teaching contexts, and in so doing, elaborate on their potential instantiation in education. Micah Newman targets emergence and supervenience, key concepts related to the micro-macro relationships in chemistry. He provides a model for teaching chemistry with the potential to enhance fundamental understanding of chemistry. Pierre Lazslo argues that chemistry ought to be taught in like manner to a language, on the dual evidence of the existence of an iconic chemical language, of formulas and equations; and of chemical science being language-like and a combinatorial art. Universitality and specificity of chemistry are interrogated by Mariam Thalos who argues that chemistry possesses a distinctive theoretical lens-a distinctive set of theoretical concerns regarding the dynamics and transformations of a variety of organic and nonorganic substances. While she agrees that chemical facts bear a reductive relationship to physical facts, she argues that theoretical lenses of physics and chemistry are distinct. Manuel Fernandez-Gonzalez discusses the concept of pure substance, an idealized entity whose empirical correlate is the laboratory product. A common structure for knowledge construction is proposed for both physics and chemistry with particular emphasis on the relations between two of the levels: the ideal level and the quasi-ideal level. Ebru Kaya and Sibel Erduran focus on concept duality, chemical language and structural explanations, to illustrate how chemistry textbooks could be improved with insights from philosophy of chemistry. They provide some example scenarios of how these ideas could be implemented at the level of the chemistry classroom. Vicente Talanquer presents a case that dominant universal characterizations of the nature of science fails to capture the essence of the particular disciplines. The central goal of this position paper is to encourage reflection about the extent to which dominant views about quality science education based on universal views of scientific practices may constrain school chemistry. 
Activities, practices and values of chemistry are interrogated in a third set of papers. Earley recommends that chemistry educators shift to a different 'idea of nature', an alternative 'worldview.' Andoni Garritz illustrates how teaching history and philosophy of physical sciences can illustrate that controversies and rivalries among scientists play a key role in the progress of science and why scientific development is not only founded on the accumulation of experimental data. The case of quantum mechanics and quantum chemistry is used as an example because it is historically full of controversies. Marcos Antonio Pinto Ribeiro and Duarte Costa Pereira illustrate how pluralism in philosophical perspectives can result in different cognitive, learning and teaching styles in chemical education. Their paper reports on the authors' experiences in Portugal in drafting structural ideas and planning for the subject "didactic of chemistry" based on the philosophy of chemistry. Veli-Matti Vesterinen, Maija Aksela and Jari Lavonen assess how the different aspects of nature of science (NOS) were represented in Finnish and Swedish upper secondary school chemistry textbooks. They present an empirical study where dimensions of NOS were analyzed from five popular chemistry textbook series.

Joseph Amparo Vilches and Daniel Gil-Perez reflect on the UN Decade of Education for Sustainable Development and how chemical education for sustainability remains practically absent nowadays in many high school and university chemistry curricula all over the world. They explore the belief that genuine scientific activity lies beyond the reach of moral judgment is logically. They propose possible contributions of chemistry and chemical education to the construction of a sustainable future. Jesper Sjostrom is concerned with Bildung-oriented chemistry education, based on a reflective and critical discourse of chemistry. This orientation is contrasted with the dominant type of chemistry education, based on the mainstream discourse of chemistry. Bildung-oriented chemistry education includes not only content knowledge in chemistry, but also knowledge about chemistry, both about the nature of chemistry and about its role in society.

Overall the set of papers illustrate the relevance of philosophy of chemistry for chemical education. We witness examples of relevance in the curriculum, textbooks, teaching and learning. The scholarship in the area is ripe for further studies. The fundamental questions such as "What is chemical knowledge and how does it develop? What criteria, standards and heuristics shape its development?" are directly relevant for ensuring that teaching and learning environments are effectively structured and resourced for sound and deep understanding of chemistry (Erduran 2009). While theoretical investigations can help orient the design of curriculum content informed by significant philosophical issues in chemistry, the genuine implementation of such curricula will demand more than rhetoric. Teachers' role in the implementation of meta-perspectives on chemistry is crucial. In this sense, a great responsibility rests on teacher educators in developing teachers' understanding of the nature of chemistry. Some crucial questions are thus raised for teacher education:

What pedagogical content knowledge do teachers need to have in order to support the learning of philosophical themes in chemistry?

What would assessments of philosophical understanding of chemistry learning look like when such conventionally unfamiliar goals are set for chemical education?

How can teachers provide formative as well as summative assessments to learners when philosophical perspectives are included in the learning outcomes?

A final reflection on the interactions of philosophy of chemistry and chemical education research: If these domains are to be fruitfully linked-or as Scerri would say, if they were to be miscible - a reciprocal relationship in their communication, articulation and synthesis will be essential. The complexity with educational research is that educators operate not 
only relative to the features of the domain they are investigating but also are guided by a multidisciplinary perspective. The goals and aims of education do not necessarily correspond to the goals and aims of chemical or philosophical research. Teaching and learning are complex phenomena that demand not just the understanding of disciplinary knowledge and practices, but also other factors such as educational policy, learner identities and so on, appealing to a diverse set of foundational disciplines such as cognitive science, sociology, psychology and politics.

Beyond a consistency with philosophy of chemistry, arguments in chemical education need to be mindful of existing knowledge on learning and pedagogy. In this sense, there is not only the task of transforming ideas from philosophy of chemistry to be usable and relevant for chemical education research and practice but also forging consistency with other goals including policy and curricular goals. After all teachers do not function in idealised circumstances and they are bound by the policy initiatives of the times. Eventually empirical validation of theoretical input from philosophy of chemistry in chemical education practice will be important to warrant the inclusion of this orientation to chemical education in curricular policy. In particular the impact of philosophical perspectives on the quality of chemistry learning will be paramount for its eventual uptake in education. Some anecdotal evidence already suggests that philosophical perspectives on chemistry can have a positive influence on learners' attitudes:

I didn't realise that many of my impressions, experiences and feelings concerning science as a whole might be explained by the fact that some natural sciences have had the privilege of defining the nature of science on behalf of them all. Being a student, I always felt inferior to the physics people. Suddenly, when reading a paper on philosophy of chemistry, I realised: that's because the physicists made the rules (Erik Fooladi, Volda University College, Norway, Personal Communication on 27th January 2012).

Acknowledgments I would like to thank Michael Matthews for soliciting this special issue and for his guidance. Furthermore, I acknowledge and thank the referees for their time and efforts in the review process. Theirs is an entirely unrewarded labour but an intellectual labour that is essential to the quality and thus utility of published work. They are named at the end of the issue.

\section{References}

Erduran, S. (2001). Philosophy of chemistry: An emerging field with implications for chemical education. Science \& Education, 10, 581-593.

Erduran, S. (2009). Beyond philosophical confusion: Establishing the role of philosophy of chemistry in chemical education research. Journal of Baltic Science Education, 8(10), 5-14.

Good, R. J. (1999). Why are chemists turned off by philosophy? Foundations of Chemistry, 1, 65-96.

Kauffman, G. B. (1989). History in the chemistry curriculum. Interchange, 20(2), 81-94. Reprinted in Matthews, M. R. (Ed.). (1991). History, philosophy and science teaching: Selected readings (pp. 185-200). Toronto: OISE Press.

Scerri, E. (1997). Are chemistry and philosophy miscible? Chemical Intelligencer, 3, 44-46.

Scerri, E. (2000). Philosophy of chemistry - a new interdisciplinary field? Journal of Chemical Education, 77(4), 522-525.

Van Brakel, J. (2000). Philosophy of chemistry: Between the manifest and the scientific image. Leuven: Leuven University Press. 